\title{
Assessing the promise of user involvement in health service development: ethnographic study
}

\author{
Nina Fudge, research associate, ${ }^{1}$ Charles D A Wolfe, professor of public health,, ${ }^{1,2}$ \\ Christopher McKevitt, senior research fellow ${ }^{1}$
}

'Division of Health and Social Care Research, King's College London, London SE1 3QD

${ }^{2}$ National Institute for Health Research Comprehensive Biomedical Research Centre, Guy's and St Thomas' NHS Foundation Trust, London

Correspondence to: N Fudge nina.fudge@kcl.ac.uk

doi:10.1136/bmj.39456.552257.BE

\section{ABSTRACT}

Objectives To understand how the policy of user involvement is interpreted in health service organisations and to identify factors that influence how user involvement is put into practice.

Design Ethnographic study using participant observation, interviews, and collection of documentary evidence. Setting A multiagency modernisation programme to improve stroke services in two London boroughs.

Participants Service users, National Health Service managers, and clinicians.

Results User involvement in the programme was initiated and led by professionals. Professionals determined the areas of service improvement service users could participate in. A wide range of activities were considered "user involvement," from patient satisfaction surveys to service users delivering peer support. Involvement tended to be most active in the least technical areas and areas with least input from clinicians. Factors that might explain this included organisational structure, the vagueness of the concept of user involvement, the value attributed to service users' experiential knowledge, and variations in professional and service user understandings of and commitment to involvement. The gains of involvement were harder to identify in terms of impact on services. More evident were the personal gains for those involved: satisfaction of feeling listened to by professionals, social opportunities of meeting others in a similar situation, and increased knowledge about stroke and services available. Conclusions User involvement may not automatically lead to improved service quality. Healthcare professionals and service users understand and practise user involvement in different ways according to individual ideologies, circumstances, and needs. Given the resource implications of undertaking user involvement in service development there is a need for critical debate on the purpose of such involvement as well as better evidence of the benefits claimed for it.

\section{INTRODUCTION}

Increasing rates of chronic disease, the need to contain costs, and raised patient expectations lie behind efforts to reform healthcare services. ${ }^{1}$ Reforms to the United Kingdom's National Health Service include efforts to transform the relationship between patients and professionals. Patients are being encouraged to exercise greater control over their own health care and to become more involved in the development of health services. ${ }^{2-4}$ The Department of Health promotes the involvement of patients and the public in decisions about the planning, design, development, and delivery of local services, with the promise that this will lead to improved services and better outcomes for patients. ${ }^{5}$ Policy documents are, however, less clear about how involvement should be undertaken. They cite a raft of arrangements that fall under the umbrella of involvement: patient choice, patient surveys, Patient Advice and Liaison Services, patient forums, and networks, Overview and Scrutiny Committees, complaints procedures, NHS foundation trust boards, and the duty to consult and involve patients and the public in the planning and development of health services. ${ }^{6}$ Evidence of the relationship between user involvement and improved outcomes is, however, weak. ${ }^{7-9}$ Several authors have commented on the lack of a precise definition of user involvement and that the aims of user involvement are multiple and go beyond improving health care. ${ }^{1011}$ In policy documents user involvement is presented as a quality issue, attributed with the capability to make improvements to services. However other analysts have explained the phenomenon of user involvement from several philosophical and political perspectives: consumerism, democracy and citizenship, and the rise of patient pressure groups. ${ }^{12}$

These factors highlight the need for increased understanding about how the policy of user involvement is interpreted in health service organisations and how these interpretations shape how user involvement is put into practice. To elucidate these questions we carried out an ethnographic study ${ }^{13}$ of an initiative to involve people with stroke and their relatives (service users) in the modernisation of stroke services.

\section{METHODS}

Stroke services, from acute to long term care, have been recognised as failing to meet the needs of patients and their families. ${ }^{14}$ In 2004 a three year programme of service improvement was initiated to modernise stroke services in two London boroughs, with charitable funding. The programme was delivered by NHS 
employees and clinicians and aimed to reduce the number of first time strokes and to modernise acute and community stroke services. The two inner city boroughs where the fieldwork took place have ethnically diverse populations. Levels of deprivation and deaths from stroke are higher than the national average. $^{1516}$

\section{Data collection}

Since our study was based within a programme of stroke research at King's College London, whose earlier findings had been key to establishing the need for the programme, access to the programme was easily negotiated. Fieldwork began in December 2004, at the beginning of the programme before service users were recruited, and continued for just over two years. It consisted of participant observation, collection of documentary evidence, and semistructured interviews (box 1) to record how user involvement was implemented and maintained, data on participants, activities, and outputs. Participant observation entailed working with programme staff, participating at recruitment events, and programme meetings. The researcher (NF) made detailed ethnographic notes and kept a reflexive diary. ${ }^{17}$

We carried out semistructured interviews with service users and programme staff who had worked

\section{Box 1: Summary of data collected}

\section{Participant observation and discussions with key informants}

Four meetings to plan recruitment

Telephone contact and visits, with local voluntary and community organisations to assist with recruitment

Telephone contact with people who had had a stroke to invite them to take part in the programme

Four "join in events" to recruit people with stroke and to encourage family members to get involved

Two events at general practices to raise awareness of stroke and three planning meetings

Five taster sessions to introduce interested service users to specific project areas

Four training sessions for service users who want to be involved

Five programme management meetings

Three meetings of the training group

Twenty meetings of the user involvement subgroup

Four meetings of the information group

Programme conference

\section{Semistructured interviews}

Seven interviews with people who declined to take part in the programme

Nine interviews with people taking part in the programme

Three interviews with professionals (two programme staff and one general practitioner) working with service users on the programme

\section{Documentary sources}

Programme newsletter

Programme documents

Minutes from meetings (programme management group, user involvement subgroup, information group, training group) closely with service users (box 1). Interviews investigated professional and service user interpretations of involvement, barriers and facilitators to its implementation, and impact. We purposively selected service user interviewees to include a range of people for sex, age, and stroke severity. Interviews were tape recorded with permission and transcribed in full for analysis. When interviewees refused to be recorded $(n=3)$ we made detailed notes during the interview, which were written up immediately after the interview.

\section{Data analysis}

Data were stored and managed using QSR Nvivo 2.0 (QSR International, Melbourne, Australia). We carried out thematic analysis of the notes, reflexive diary, interview transcripts, and programme documents. Analysis was done concurrently with data collection and iteratively directed data collection. ${ }^{18}$ Every three months the researcher $(\mathrm{NF})$ wrote a summary of the fieldwork and identified emerging themes, patterns, categories, and anomalies in the data. The notes, diary, and programme documents were reread to code additional patterns and themes. These were discussed and iteratively reviewed with the principal investigator (CM). On a whiteboard we grouped these patterns and themes into larger overarching themes to understand how the interpretation of user involvement and other factors shaped its implementation in the programme. The emerging themes were reported to programme staff and service users to identify additional data that might challenge preliminary analyses. ${ }^{19}$

\section{RESULTS}

"People with stroke in the driving seat": the ethos of user involvement in the programme

From the outset user involvement was considered an important part of the programme. Programme documentation announced that service improvement would be achieved through "close collaborative working with people who have stroke in designing and delivering integrated services to support all stages of treatment, rehabilitation and learning to live with stroke" (document 1: programme proposal). No specific detail was given of how this was to be achieved. The programme was organised into four work streams overseen by a management group (figure). The fourth work stream focused on user involvement, development of the workforce, and information. It was intended as an infrastructure work stream to support the three other work streams. A manager was employed to lead on user involvement throughout the programme, supported by a working group. Initially this comprised 12 people from local voluntary sector and health service organisations, although membership decreased to five after two meetings, with many members citing other work priorities as the reason for their inability to attend. User involvement was well resourced, with funds available to employ a user involvement lead working $50 \%$ of her or his time on user involvement activities, administrative support, transport costs for service users to attend meetings, 
venue hire, and expenses for service users (although take-up of this was minimal).

\section{Recruiting and directing service users}

Two one day events were held to publicise the programme to service users and the areas in which they might participate. About 500 invitations were distributed to stroke survivors using a mixture of consecutive and convenience sampling through a community stroke register, voluntary groups, and hospital and community clinicians. Transport was offered and lunch was provided.

In total, 60 service users attended the two initial events. Recruitment was ongoing throughout the two years. Overall, details of 176 service users (158 stroke survivors, 18 carers) were entered on a user

\begin{tabular}{|c|c|c|c|c|c|c|c|}
\hline \multicolumn{8}{|c|}{$\begin{array}{c}\text { Project management group } \\
\text { Role: oversee running of programme } \\
\text { Users involved? Two service users join group as members }\end{array}$} \\
\hline \multicolumn{8}{|c|}{ Four work streams to oversee day to day running of projects to improve stroke services: } \\
\hline \multicolumn{2}{|c|}{$\begin{array}{c}\text { Prevention } \\
\text { Work stream lead: clinician. } \\
\text { One service user on steering group }\end{array}$} & \multicolumn{2}{|c|}{$\begin{array}{c}\text { Acute services } \\
\text { Work stream lead: clinician. }\end{array}$} & \multicolumn{2}{|c|}{$\begin{array}{l}\text { Community services } \\
\text { Work stream lead: primary care } \\
\text { trust service managers }\end{array}$} & \multicolumn{2}{|c|}{$\begin{array}{l}\text { Living with disability } \\
\text { Work stream lead: co-led by voluntary } \\
\text { sector and one service user }\end{array}$} \\
\hline Project & Users involved? & Project & Users involved? & Project & Users involved? & Project & Users involved? \\
\hline $\begin{array}{l}\text { Improving blood } \\
\text { pressure } \\
\text { monitoring in } \\
\text { general } \\
\text { practices }\end{array}$ & $\begin{array}{l}\text { Through steering } \\
\text { group discussions } \\
\text { and discussions } \\
\text { with service users } \\
\text { on local groups to } \\
\text { oversee } \\
\text { implementation }\end{array}$ & $\begin{array}{l}\text { Transient } \\
\text { ischaemic } \\
\text { attack clinic }\end{array}$ & $\begin{array}{l}\text { Service users } \\
\text { consulted on } \\
\text { design of patient } \\
\text { questionnaire. } \\
\text { Shadowing patient } \\
\text { walk through of } \\
\text { service }\end{array}$ & $\begin{array}{l}\text { Mapping } \\
\text { community } \\
\text { service } \\
\text { usage }\end{array}$ & None & User involvement & $\begin{array}{l}\text { None - service } \\
\text { users invited to } \\
\text { join, but no } \\
\text { interest in this } \\
\text { group }\end{array}$ \\
\hline $\begin{array}{l}\text { Scoping for project } \\
\text { on telemedicine }\end{array}$ & None & $\begin{array}{l}\text { Improving ward } \\
\text { environment }\end{array}$ & $\begin{array}{l}\text { Patient } \\
\text { questionnaires, } \\
\text { suggestion boxes }\end{array}$ & $\begin{array}{l}\text { Intensive } \\
\text { community } \\
\text { rehabilitation }\end{array}$ & $\begin{array}{l}\text { One patient wrote } \\
\text { in with feedback } \\
\text { having received } \\
\text { service }\end{array}$ & Information & $\begin{array}{l}\text { Information group } \\
\text { of } 15 \text { service users } \\
\text { established. } \\
\text { Worked on: } \\
\text { developing } \\
\text { information } \\
\text { pathway, patient } \\
\text { held records, } \\
\text { information } \\
\text { leaflet for stroke } \\
\text { unit, picture boards } \\
\text { for stroke unit, and } \\
\text { information for } \\
\text { parenting after } \\
\text { stroke }\end{array}$ \\
\hline \multirow[t]{4}{*}{$\begin{array}{l}\text { Raising awareness } \\
\text { of hypertension }\end{array}$} & None & $\begin{array}{l}\text { Thrombolysis } \\
\text { and acute } \\
\text { response }\end{array}$ & None & $\begin{array}{l}\text { Developing staff } \\
\text { competencies }\end{array}$ & $\begin{array}{l}\text { Service users } \\
\text { consulted at sign } \\
\text { off event for } \\
\text { developing staff } \\
\text { competencies }\end{array}$ & Workforce training & $\begin{array}{l}\text { Training group } \\
\text { of } 15 \text { service users } \\
\text { established. } \\
\text { Created DVD of } \\
\text { patients' } \\
\text { experiences of } \\
\text { stroke with } \\
\text { guidance on how } \\
\text { patients want to be } \\
\text { treated by } \\
\text { professionals. } \\
\text { Service users } \\
\text { involved in training } \\
\text { healthcare } \\
\text { professionals }\end{array}$ \\
\hline & & & & $\begin{array}{l}\text { Goal setting in } \\
\text { rehabilitation }\end{array}$ & $\begin{array}{l}\text { One service user } \\
\text { attended training } \\
\text { events to launch } \\
\text { scheme to } \\
\text { professionals }\end{array}$ & Peer support & $\begin{array}{l}\text { Six service users } \\
\text { trained to give } \\
\text { peer support }\end{array}$ \\
\hline & & & & & & $\begin{array}{l}\text { Long term support } \\
\text { project }\end{array}$ & $\begin{array}{l}\text { Twelve service } \\
\text { users involved in } \\
\text { setting up network } \\
\text { to provide people } \\
\text { with stroke with } \\
\text { long term support }\end{array}$ \\
\hline & & & & & & $\begin{array}{l}\text { Raising awareness } \\
\text { of stroke }\end{array}$ & $\begin{array}{l}\text { Seven service } \\
\text { users working with } \\
\text { professionals to } \\
\text { run events for local } \\
\text { population in } \\
\text { general practices } \\
\text { to raise awareness } \\
\text { of stroke }\end{array}$ \\
\hline
\end{tabular}


involvement database over the two years. Based on estimates of local stroke prevalence ${ }^{2021}$ this represents about $3.3 \%$ of stroke survivors in the study area. However, the database includes both those who went on to participate in programme activities, as well as those who attended only one event.

Service users who attended initial recruitment meetings were invited to identify their priorities for stroke service improvement. Programme staff recorded these problems but announced that one area-transportwas beyond the remit of the programme. Staff encouraged attenders to participate in one or more activities from a predefined list: training healthcare professionals, developing information, providing peer support, ensuring stroke survivors were involved in the programme, and membership of the programme management group. Training was offered to service users who wished to participate in peer support, training healthcare professionals, and the project management group, focusing on skills needed to participate and background to the NHS and the programme. Professionals who were already members of the project management group were also offered training about working with service users. Despite the stated aim to involve service users throughout the programme, in practice this was limited mainly to the infrastructure work stream (figure).

\section{User involvement activities and outputs}

The table reports the activities and outputs of user involvement across the programme work streams where service users were involved. Over the two

\section{Processes and outputs}

Area

Information
Processes

Specific group established for service users interested in developing information; additional groups established for specific material developed (patient handbook patient groups such as younger people picture menus in stroke units, information with stroke who have children; raising about parenting after stroke); events awareness events at general practices run allowed service users to share information by service users and professionals

Training healthcare Specific group established for service professionals users interested in training healthcare professionals; raising awareness events at general practices run by service users and professionals; service users attended training sessions to speak directly to professionals

Support

Training given to service users interested in providing peer support; recruiting service users to lead project to provide long term support

Programme Service users trained to take part in

management group programme management group

Acute services

Patients asked to complete patient satisfaction surveys and offer suggestions for improvement

Community services Service users consulted at "sign off' event for staff competencies

Prevention Service users invited to take part in prevention steering group

\section{community services}

Service user co-opted on to existing steering group and takes part in group accountable for work stream years of our evaluation the programme succeeded in engaging users to produce a range of outputs aimed at improving specific components of stroke care. Intuitively some outputs would seem to have higher quality because of the involvement of users. For example, interviewees asserted that involving service users ensured that the staff training and patient information materials that were developed were more relevant because they reflected the views of people affected by stroke. Furthermore, development of staff training materials used an established method, which the user involvement lead reported had been positively evaluated. Information resources developed through the programme have not been formally evaluated making it difficult to assess whether this led to improved outcomes for patients. A Cochrane review on effects of user involvement found that patient information leaflets developed with service users were more relevant, readable, and understandable to patients than those developed without input from service users, but did not reduce patient worries or anxieties. ${ }^{9}$

When asked about how their involvement had improved services, few service users could directly answer the question. They pointed to specific new services initiated within the programme such as peer support and events to raise awareness of stroke held at general practices, both needs identified during consultations with service users. However, they discussed the impact of involvement primarily in terms of personal gains. For example, they reported satisfaction in feeling that professionals were listening to them, that their ideas were acted on, and that their experience of stroke was being harnessed to help others. During fieldwork carried out in group meetings and one-off events it was common to hear service users remark that this was the first time that they had met another stroke survivor. Throughout the programme service users were observed engaging with the programme for the social opportunities it provided. Service users also described their involvement as helping to increase their knowledge and understanding of stroke.

\section{Factors limiting service user involvement}

Users were involved in a variety of projects although this was mainly restricted to those in the infrastructure work stream, and service users were less likely to be involved in technical projects. Factors that might explain this were organisational structure and responsibility for user involvement, communicating involvement, types of knowledge, and patients' and professionals' understanding of involvement.

\section{Organisational structure and responsibility for user involvement}

Although all work streams were required to involve service users, in practice the appointment of a user involvement lead and establishing a specific group for user involvement meant that user involvement became a distinct project and was harder to embed throughout the programme. The lead described her situation as a catch 22 one - it was necessary to have a dedicated 
person responsible for user involvement but that this meant colleagues could leave "doing user involvement" up to her. She could encourage colleagues working in other work streams to involve service users in their work but did not have the authority to require it or control the form that it took. Given the structure of the programme it is perhaps not surprising that user involvement was most developed in the infrastructure work stream. User involvement in the discipline specific work streams tended to take a more passive form, with use of patient satisfaction surveys and suggestion boxes or consultation with service users in the later stages of a project.

\section{Communicating involvement}

Service users were more interested in participating in projects related to training healthcare professionals, developing information, and supporting stroke survivors than taking on project management roles. Of five service users who underwent training to participate in the programme management group only two members retained their membership throughout the fieldwork period. No service users were interested in joining the user involvement subgroup - a group to manage the involvement of service users in the programme. By comparison the training, information, and peer support related projects had up to 15 members regularly attending meetings. When recruiting to these projects, staff could point to tangible outputs or products, such as developing information leaflets or good practice guidance to inform staff training, unlike other projects with less tangible outputs such as reorganising community clinical services, or project management.

\section{Box 2: Transformation from patients to service users}

The user involvement lead and I arrived at the surgery where the event to raise awareness about stroke was to take place. The service users, who were part of the planning group and would help run the event, were already there in the surgery waiting room. The user involvement lead went up to the front desk and asked the receptionists where we should go for the stroke raising awareness event. One of the receptionists got up from behind the front desk and began to lead us through a side door into the larger room where the event was going to be held. The receptionist tried to stop the service users from entering the room, telling them that the event wasn't due to begin for another hour or so. The user involvement lead had to explain to the receptionist that these people were part of the organising team and that although they had all had strokes they were not patients from the GP surgery wanting to attend the event. The receptionist reluctantly let us all through. (Field notes from an event to raise awareness of stroke, 7 December 2005)

Sarah, one of the professionals on the programme, suggested that we move on to the next item and asked her colleague Simon if he wanted to introduce the questionnaire. Simon told the group about TIAs (transient ischaemic attacks) or mini strokes and explained that part of the work of the programme is to get more people going to TIA clinics and then to assess how the clinic is being run from the perspective of clinic users. Simon handed out a questionnaire and explained to the group how he had designed this questionnaire and that he had "brought it to you guys" to see if it was understandable and the right way to "check patient feedback." There was a bit of confusion from the service users-some people started to fill in the questionnaire while others said they did not see how the questionnaire was relevant to them since they had not had a TIA or been to this clinic before. Nora said that her husband had had a mini stroke and she would take the questionnaire home and ask him to fill it in. Simon said that it was OK, she did not need to do that. (Field notes from a meeting of the information group, 29 November 2005)
Service users also compared participating in time limited projects with a defined output with the longer term commitment required of management roles.

\section{Types of knowledge}

Projects that service users were involved in required them to draw on their own experience of being a patient or carer. Programme staff promoted experiential knowledge as useful for educating health professionals and supporting other stroke survivors.

Clinical service development was seen to require a different kind of knowledge. Evidence suggests that professionals believed service users would not be capable of participating in some aspects of the programme because they lacked the necessary technical knowledge. For example, when the user involvement lead asked colleagues why service users had not been involved in a project to map usage of community services, they suggested that the work would have been too difficult for service users to undertake.

On several occasions during fieldwork incidents were observed suggesting that "involvement" requires both professionals and service users to reconceptualise the traditional category of patient to accommodate the notion that service users have a contribution to make to service planning and development, a transformation that was not always easily achieved (box 2).

\section{Patient and professional understandings of involvement}

The range of interpretations that service users and professionals had of "user involvement" and what it should entail may have further influenced the forms that this took in the programme.

Professionals had a variety of views of what involvement entailed, linked to their own background and career history. Professionals responsible for involvement and those happy to undertake involvement had experience of involving service users in their work, tended to have backgrounds in voluntary and social care fields, and tended not to be involved in the more clinical and technical aspects of the programme. These professionals displayed a moral and political commitment to the ethos of involvement and belief in the engagement of citizens in public decision making. Other professionals saw involvement as a NHS requirement, tending to involve service users at the end of the process to get approval for a product or service. Both these interpretations were able to coexist without raising problems.

Service users gave a range of reasons for participating in the programme, which suggests that involvement was not understood solely as an opportunity to be involved in service development. Motivation to participate included the right for patients to have a say about the services they use, the chance to meet others in a similar situation, finding out about developments in stroke medicine, accessing health or social care services, and attending as part of the process of recovery from stroke (box 3). 


\section{DISCUSSION}

Involving service users in service development is an NHS policy requirement promoted to encourage patients to exert greater control over their health care and improve health services. Our ethnographic study shows that although the programme embraced the policy of user involvement and aimed to involve users in all its activities, programme staff largely determined how user involvement was put into practice. Little evidence was found of user involvement directly contributing to improved quality of services except in a few limited areas. The contribution of service users centred on the application of their experiential knowledge to develop services and materials to deliver peer support, information, and staff training. Their lack of technical knowledge was seen to preclude their participation in some activities. Thus, as other studies have also found, professionals control the interpretation of involvement and the ways that service users are involved. ${ }^{22-25}$ This may have implications for the ability of user involvement to bring about fundamental change.

\section{Concepts of involvement}

We found that different concepts of user involvement coexisted within a single organisation. As user involvement was loosely defined in programme documentation there was little dissent about whether activities constituted "real" involvement or not. Previous studies have looked at responses of different professional categories to the idea of user involvement suggesting responses ascribe to the interests of the particular discipline. ${ }^{2627}$ Here we observed differences within professional and service user groupings based on individual ideologies, circumstances, and needs. Within professional groupings we identified two categories. Firstly, professionals who viewed user involvement as an exercise in democracy and promoted patients' expertise as valid as that of professionals were identified. In contrast there were those who unquestionably enacted out the policy of involvement as a directive to be implemented as part of a patient centred NHS.

Despite some promoting the philosophy of patient expertise, however, the domains in which patients could exert their expertise were limited. The involvement of stroke survivors in the clinical work streams was limited to more passive forms of involvement, such as patient satisfaction surveys or one-off consultations. This compared with involvement in areas such as training healthcare staff, developing information, and peer support where user involvement was more extensive and service users were more active in the development and delivery of these services. Thus user involvement in this setting did not transform patient and professional relationships in the way that policy documents promoting involvement imply.

Among services users we observed several motives for participating in the programme: desire to improve services, social opportunities, increasing knowledge of stroke, and accessing services. Although it is probably necessary for those involved to have a range of benefits in return for their participation, the implication of this calls into question the ability of user involvement to improve services if this is not the primary motivation of those involved.

Despite the significant impact of stroke on patients and family members who care for them ${ }^{2829}$ and the long history of poor quality stroke services in the UK, ${ }^{14} 30$ user involvement in the specialty of stroke is only now beginning to emerge. Patients with stroke have not organised themselves into activist grass roots movements, as has occurred in health areas such as HIV/ AIDS, maternity services, breast cancer, and mental health. ${ }^{2531-33}$ Among the stroke population is a high proportion of older adults, people with disabilities, and those who are socially isolated. ${ }^{28}$ This raises questions about whether characteristics of certain patient groups make user involvement more or less difficult to implement.

\section{Representativeness of service users}

Only a small percentage of the prevalent stroke population was involved, and those most active were a small, dedicated group of service users, with most participating in more than one project within the programme. The resources (time and money) required to recruit and sustain this small group were considerable. This raises two questions: how do we justify the cost of user involvement when the outcomes are unclear, and how representative of the stroke population was this small group of service users?

The debate on representativeness of service users is long standing. ${ }^{34}$ Promoters of involvement have insisted that we focus on inclusion and diversity of service users rather than representativeness. ${ }^{35}$ Our research suggests that more work is needed to ascertain whether the views of those involved are the same as those not involved and whether user involvement is leading to inequalities - providing benefits to those involved over those who are not. The small numbers of service users involved and the range of interpretations of what involvement is also question the assumption of user involvement policy that patients and the public universally want to participate in making decisions about health services. ${ }^{10}$

\section{Strengths and limitations of the study}

Our study has several limitations. Firstly, our ethnography of a unique programme to modernise stroke services is not immediately generalisable to other examples of service modernisation in which service users are involved. The questions we raise from our findings are, however, applicable more broadly to the policy of user involvement. Secondly, our evaluation was carried out over two years of a three year project. Our ethnography provides only part of the story of a project within which the involvement of service users continues to develop. A stroke service user network is being established to continue three projects: peer support, training healthcare professionals, and developing information resources. This further emphasises 
Box 3: Service users' interpretation and understanding of user involvement

\section{A right for patients to have a say about the services they use}

Service user 4: It's nothing new-this has been going on for centuries you know so why would we think it is something new? Women had to fight for their rights, tie themselves to railings things like that to vote so why would we think it is something new? You have to campaign for anything you want-it's never given to you. (Interview, 19 January 2006)

Carer at the introductory event: If you let the NHS decide you won't get the right answers. If you speak to users you will get the answers. Doctors must form services based on what people need. (Field notes from an event, 21 March 2005)

\section{Opportunity to meet others in a similar situation}

Service user 5: Well as I said before, it [participating in the programme] made me go to my doctor and find out as to, you know, what happened to me when I had a stroke which I probably wouldn't have bothered to do. Apart from the fact of hearing of other people's experiences of stroke cos I mean the people there the experiences are so different. You know there's Vera who had lots of small ones before the main one and others that have had a small one and then the big one... so that was a positive thing for me to sort of go and find out... yeah and you know meeting people and finding out their different experiences. It's nice to meet new people isn't it? (Interview, 25 January 2006)

\section{Finding out about the latest developments in stroke medicine}

Interviewer: Why did you want to go to the event?

Service user 6: I wanted to see if there was any progress made like you know.

Interviewer: What kind of progress?

Service user 6: Discovered any new medical things like you know. Cos I mean you read in the papers, especially in The Mail today it's all medical you know and there's things in there I mean there's a man who's just had all his stomach took away and things like that and you just don't realise such things can happen-I know they do some wonderful things you know. But I went to see if there's any, as I say, new effects come on the market. (Interview, 9 August 2005)

\section{Accessing health or social care services}

Mrs James attended a number of the one-off events, but didn't want to take part in any of the smaller projects. Her main concern at the events was her housing situation: she and her husband, who was in a wheelchair as a result of his stroke, were housed in the top floor of a high rise block of flats with lifts that worked intermittently, making it impossible for them to leave the flat in case the lifts were broken and they couldn't get back up to their flat. Mrs James told her story to some senior social care managers who were also present at the event. One in particular told her who she needed to phone to get things sorted out and then gave her his card and told her to contact him directly if she still didn't have any luck with getting things sorted out. (Field notes from an event, 11 October 2005)

\section{A service to aid recovery from stroke}

I asked Grace how she heard about the Join In Event. She said that she heard about it at the day centre: a lady was there who was talking about it and then they sent her a letter asking her if she wanted to go to the event. I asked Grace why she decided to go to the event. She said that she just wants "to know what's happened, what's going on." I asked her what she thought of the event. She said that it was "quite alright" but that she didn't think she could improve any more than she already had: five years after her stroke and she still couldn't move her hand properly. I asked her what she thought the purpose of the event was. Grace said that maybe it was for other people who had "just had a stroke maybe two or three months ago," but when you have had a stroke quite a long time ago there isn't really anything that they can do to improve things for you. (Field notes from telephone interview, 5 September 2005)

I spoke to Mr Roberts about the Join In Event and whether he was able to come or not. $\mathrm{Mr}$ Roberts said the he wasn't sure he'd "get much value out of the meeting." Mr Roberts explained that he had had a mild stroke and apart from memory loss and slight vision problems was "reasonably fit." He said that he "couldn't see how [he] could contribute much." Mr Roberts said that he thought that the meeting is basically needed for other people more badly affected by stroke. (Field notes from telephone conversation, 5 October 2005)

the time required to fully develop and embed user involvement within an organisation. Thirdly, the ethnographic approach we have taken is an interpretive one and does not provide the only or most legitimate account, but an account that is open to discussion and critique. ${ }^{13}$

Other studies looking at user involvement in practice have tended to use qualitative methods such as interviews and non-participant observation. ${ }^{2223}$ The strength of this study is the ethnographic approach incorporating participant observation over a sustained period allowing observation of insider insights and what participants actually do as opposed to what they say they do. ${ }^{36}$ We shared our findings with study participants to challenge our preliminary analysis. ${ }^{19}$ There were some minor factual corrections but no disagreement with the analysis we presented.

\section{Implications for policy and practice}

Our findings have implications for those concerned with developing the evidence base for the effects of user involvement. There have been calls for use of randomised controlled trials to provide evidence of impact. ${ }^{9}$ Through our ethnography we have provided evidence of the multiple meanings assigned to user involvement and multiple outputs of involvement, a theme discussed in published opinion pieces ${ }^{11}$ and reported in research. ${ }^{10}$ This suggests that identifying the active component and anticipated outcomes of user involvement necessary for undertaking a randomised controlled trial to provide evidence may be difficult. Other evaluation methods may be more appropriate for evaluating user involvement as a complex intervention, taking into account factors that may shape and constrain user involvement in health care.

In terms of practice our ethnography suggests that the presumed benefits of the policy may not be easily achieved. Our study has shown that a small proportion of the stroke population actively participated, raising questions about who gets involved and whether this might lead to inequalities if only a small group experience the benefits of involvement. It is perhaps also an assumption of the policy that everyone wants to be involved. Characteristics of the patient group involved may also determine the form that user involvement takes and the time it takes to embed within an organisation. Unlike the classic examples of activist led involvement (HIV/AIDS, mental health, and breast cancer), user involvement in this study was professionally led. Had a stroke activist group existed, involvement in this study may have looked different from that observed. What we have observed is the start of something that might develop in a different direction as the roles of patients with stroke transform. As a result of the multiple meanings, philosophies, and outcomes of involvement, user involvement will not necessarily be able to generate radical change to health services as the policy might suggest. Greater debate is required among those implementing the policy as to why user involvement is desired, what is hoped to be achieved by increasing involvement of service users in the health service, as well as more evidence and critical analysis of the improvements user involvement is said to bring. 


\section{WHAT IS ALREADY KNOWN ON THIS TOPIC}

Involving patients and the public in health service development is said to lead to better

services and improved outcomes

Evidence showing the effects of this on the quality and effectiveness of services is limited

\section{WHAT THIS STUDY ADDS}

Professionals determine how service users will be involved in service development and this may limit change that can be achieved

Small numbers of service users were "involved," with personal gains for them

Service users' experiential knowledge is valued because it seems to provide information that will improve delivery of care
11 Florin D, Dixon J. Public involvement in health care. BMJ 2004;328:159-61.

12 Harrison S, Dowswell G, Milewa T. Guest editorial: public and user 'involvement' in the UK National Health Service. Health Soc Care Community 2002;10:63-6.

13 Savage J. Ethnography and health care. BMJ 2000;321:1400-2.

14 National Audit Office. Reducing brain damage: faster access to bette stroke care. 2005. www.nao.org.uk/publications/nao_reports/0506/0506452.pdf.

15 Association of Public Health Observatories, Department of Health. Community health profile for Lambeth 2006. www. communityhealthprofiles.info.

16 Association of Public Health Observatories, Department of Health. Community health profiles for Southwark 2006. www. communityhealthprofiles.info.

17 Davies CA. Reflexive ethnography. A guide to researching self and others. London: Routledge, 1999.

18 Hammersley M, Atkinson P. Ethnography: principles in practice. $2 \mathrm{n}$ ed. London: Routledge, 1995.

19 Murphy E, Dingwall R. Qualitative methods and health policy research. New York: Walte de Gruyter, 2003.

20 Quality and Outcomes Framework database 2005-Lambeth PCT. www.gpcontract.co.uk/pctarea.php?

orgcode $=5$ LD\&area $=21$ \&year $=5$ (accessed 24 May 2007).

21 Quality and Outcomes Framework database 2005-Southwark PCT. www.gpcontract.co.uk/pctarea.php? orgcode $=5$ LE\&area $=21$ \&year $=5$ (accessed 24 May 2007)

22 Hodge S. Participation, discourse and power: a case study in service user involvement. Crit Soc Policy 2005;25:164-79.

23 Rutter D, Manley C, Weaver T, Crawford MJ, Fulop N. Patients or partners? Case studies of user involvement in the planning and delivery of adult mental health services in London. Soc Sci Med 2004;58:1973-84

24 Wellard S, Lillibridge J, Beanland C, Lewis M. Consumer participation in acute care settings: an Australian experience. Int / Nurs Pract 2003;9:255-60.

25 Roy CM, Cain R. The involvement of people living with HIV/AIDS in community-based organizations: contributions and constraints. AIDS Care 2001;13:421-32

26 Daykin N, Sanidas M, Tritter J, Rimmer J, Evans S. Developing user involvement in a UK cancer network: professionals' and users' perspectives. Crit Public Health 2004;14:277-94.

27 Milewa T, Valentine J, Calnan M. Community participation and citizenship in British health care planning: narratives of power and involvement in the changing welfare state. Sociol Health Illn 1999;21:445-65.

28 Wolfe CD. The impact of stroke. Br Med Bull 2000;56:275-86.

29 Low JT, Payne S, Roderick P. The impact of stroke on informal carers: a literature review. Soc Sci Med 1999;49:711-25.

30 King's Fund. Consensus conference. Treatment of stroke. BMJ 1988;297:126-8.

31 Brown P, Zavestoski S. Social movements in health: an introduction. Sociol Health Illn 2004;26:679-94.

32 Kolker ES. Framing as a cultural resource in health social movements: funding activism and the breast cancer movement in the US 19901993. Sociol Health Illn 2004;26:820-44.

33 Fletcher G. Building sustainable partnerships in user involvement. The Obstetrician and Gynaecologist 2003;5:218-20.

34 Crawford MJ, Aldridge T, Bhui K, Rutter D, Manley C, Weaver T, et al. User involvement in the planning and delivery of mental health services: a cross-sectional survey of service users and providers. Acto Psychiatr Scand 2003;107:410-4.

35 Beresford P. User involvement, research and health inequalities: developing new directions. Health Soc Care Community 2007;15:306-12.

36 Lambert H, McKevitt C. Anthropology in health research: from qualitative methods to multidisciplinarity. BMJ 2002;325:210-3.

Accepted: 14 November 2007 